\title{
Going Online to Make Learning Count
}

International

Review of

Research in Open

and Distance

Learning

Vol. 12.1

January -2011

\section{Cathy Brigham and Rebecca Klein-Collins}

Council for Adult and Experiential Learning, USA

\begin{abstract}
Adult students often come to higher education with college-level learning that they have acquired outside of the classroom - from the workplace, military service, self-study, or hobbies. For decades, many forward-thinking colleges and universities have been offering services to evaluate that learning and award it college credit that counts towards a degree. However, for a range of reasons, not every institution can offer prior learning assessment (PLA) in every discipline or for every student. With funding from several U.S. philanthropic organizations, the Council for Adult and Experiential Learning (CAEL) is launching Learning Counts, a national online service that will offer students a range of opportunities to have their learning evaluated for college credit. This online service will expand the capacity of institutions offering PLA to students and provide an efficient and scalable delivery mechanism for the awarding of credit through PLA.
\end{abstract}

Note: The term prior learning assessment or PLA is the preferred term in the U.S. for the recognition of prior learning. It may be more familiar to readers as assessment of prior learning (APL), prior learning assessment and recognition (PLAR), or recognition of prior learning (RPL).

Keywords: Online learning; PLAR 


\section{History and Role of PLA}

Prior learning assessment (PLA) is a process used by colleges and universities in the United States, Canada, and many other countries to evaluate learning acquired outside the classroom. Assessments are conducted for the purpose of assigning academic credit. Many adults welcome this opportunity. It helps them accelerate their progress toward a degree or certificate and can hold down their costs. Common ways individuals have acquired college-level learning include

- corporate or military training,

- work experience,

- civic activity,

- independent study.

In the U.S., methods to assess prior learning encompass multiple formats, including standardized exams, such as those delivered by the College Board, the Excelsior College Examination Program, or the DANTES Subject Standardized Tests Program; American Council on Education (ACE) Guides to credit recommendations for civilian and military training programs; evaluations of local training programs by local colleges; campus challenge exams; and portfolio assessments of experiential learning.

PLA advocates have long argued that by helping individuals earn credits faster and at a lower cost, PLA can significantly contribute to ongoing progress towards a degree or certificate. Lumina Foundation for Education funded a recent study conducted by CAEL which indicated that PLA students had better outcomes, particularly in terms of graduation rates and persistence, than other adult students:

- Fifty-six percent of PLA students earned a post-secondary degree within seven years, while only $21 \%$ of non-PLA students did so.

- Of those students who had not earned a degree within seven years, more than half of the PLA students had earned $80 \%$ or more of the credits needed for graduation versus only $22 \%$ of non-PLA students.

- Compared to non-PLA students, PLA students earning bachelor's degrees saved an average of between 2.5 and 10.1 months in earning their degrees, and those earning an associate's degree saved an average of between 1.5 and 4.5 months in earning their degrees (Klein-Collins, 2010).

These findings that PLA students had better academic outcomes than non-PLA students support claims that PLA is a strategy that will help adults earn degrees and progress more quickly toward their goals.

The challenge for students, however, is that PLA is not universally available. Many colleges and universities lack the capacity to provide a comprehensive set of PLA services. Portfolio assessment, in particular, can have significant administrative and faculty costs, and it can be 
difficult for a single institution to have enough trained faculty to assess portfolios in a range of subject areas.

\section{The Learning Counts Solution}

Because not every institution has the capacity to offer portfolio assessments across a range of disciplines or to large numbers of students, the Council for Adult and Experiential Learning (CAEL) is launching a national online PLA service called Learning Counts. This service will conduct assessments of prior learning for consideration of college-level equivalency in liberal arts and professional areas and will also assess occupational and technical learning accomplished through on-the-job experiences.

CAEL is developing Learning Counts in partnership with the American Council on Education (which evaluates military, corporate, and other non-institutional training for credit) and the College Board (which offers the standardized CLEP exams). Through an online web portal for Learning Counts, CAEL will offer portfolio courses and faculty evaluations of student portfolios. The site will refer students to the College Board for standardized exam services and to ACE to determine whether the student's military or corporate training has been evaluated for college credit. Similarly, ACE and the College Board will refer their clients to Learning Counts for individualized portfolio evaluation services, as appropriate. ACE will provide transcripts for all PLA credits earned through Learning Counts and send them to the students' choice of post-secondary institutions.

During a pilot stage, Learning Counts will work with a group of up to 100 post-secondary institutions, to serve students on a referral basis. The vision is for Learning Counts to eventually serve thousands of students per year, including students not yet affiliated with a specific institution.

Specifically, the Learning Counts Center will offer the following services:

- an online course in prior learning assessment, helping students to understand the full range of PLA options available to them and assisting them in assembling a portfolio that reflects their prior and experiential learning;

- academic advising to students, especially in the area of PLA;

- matching submitted portfolios to qualified faculty assessors who will review the portfolio for college-level learning;

- access to trained faculty who will assess the portfolios, according to CAEL's quality standards;

- links to ACE and the College Board, providing transparent access to a full suite of PLA opportunities for individuals and agencies;

- transcripts of students' complete history of prior learning through ACE. 


\section{Who Will Benefit from this Service}

The target population for Learning Counts is almost incomprehensibly large. Certainly, those who have not yet completed postsecondary credentials are a primary target audience envisioned by CAEL. Learning Counts will serve as a resource for these individuals, some already enrolled, some considering enrollment, some who are only now considering their college options, and some who have just completed their high school degree or its equivalency, by offering evaluation of their experiential learning for undergraduate credit. These individuals may already be matriculated at an institution of higher learning or may be unaffiliated with any institution. Either way, they can approach Learning Counts independently and request a review of their prior learning for college credit. Applying for and receiving college credit through such a PLA process will help many students overcome the barriers of accessibility, affordability, and low aspirations.

Other individuals who may use the Center include workers in transition, with a special focus on low-income workers who wish to document skills mastered in previous work environments or other contexts. While it may not be the final goal of all low-income adults to complete an undergraduate degree, these individuals may be interested in postsecondary certification and may also find value in compiling their skills and having them evaluated against a consistent system of assessment so they can be better prepared to present and document their skills when considering future job transitions.

The Learning Counts Center will also be a resource for returning veterans and other service men and women. While members of the military have access to formal assessment of some of their training via ACE, not all of the learning opportunities from a military career can be captured through this system. Learning Counts, by offering the portfolio course and assessment, will provide a flexible and easily accessible way for both veterans and active-duty military to have their learning assessed for college credit, thereby accelerating their progress toward a postsecondary credential or degree that will help them transition into a civilian career.

Similarly, institutions of higher learning can use Learning Counts as a support for their everstrained resources. Hundreds of colleges and universities across America are clamoring for assistance in the area of prior learning assessment. They recognize the need for developing a new, or enhancing their current, model in order to better meet the needs of their current and prospective students, as well as their communities and local economies. Yet even though these institutions find themselves eager to improve in this area, they are unable to do so because of a combination of a lack of resources (both personnel and financial) and a lack of expertise in prior learning assessment. Colleges and universities could choose to use Learning Counts as a resource, either as their primary way to evaluate portfolio submissions from students or as a way to augment their existing programs.

By no means do we suggest that Learning Counts would become something universally adopted by colleges across the country. There are many exemplary programs at individual colleges and universities that function well, are robustly staffed and funded, and serve their students best by being offered locally. Many other schools, however, want a PLA program but do not have the 
resources to launch one that can adequately support their students. Learning Counts would be a resource to those institutions suffering a lack of staff support, financial resources, or experience and expertise in the area of prior learning assessment.

One final group that will utilize Learning Counts is the business community. Employers actively promoting the development of their workforce will be grateful for an opportunity to have their employees, as well as their corporate professional training sessions (both formal and informal), evaluated for college-level credit. Evaluations would be done either on a person-by-person basis through the Center or as part of the training-program evaluations performed by the American Council on Education. These evaluations will serve as yet another way to demonstrate an organization's commitment to workplace learning and professional development. In addition, employees who earn prior-learning credit will advance more quickly and economically towards acquiring the post-secondary credential that will benefit both them and their employer.

\section{Getting There from Here}

In the fall of 2010, CAEL selected a diverse group of institutions (numbering approximately 100), representing all categories of higher-education institutions, as well as industry and workforce boards, to participate in the pilot phase of Learning Counts. In order to ensure broad representation, our pilot institutions will include representation from the military, organizations within high-need or emerging industries, groups providing direct services to in-transition workers (such as workforce investment boards or WIBs), and postsecondary institutions. Our outreach to the educational community has included community colleges and four-year universities, public and private institutions, online and face-to-face programs, programs serving traditional and nontraditional students, and both not-for-profit and for-profit institutions.

CAEL expects the first cohort of Learning Counts participants to begin submitting portfolios for evaluation in early 2011.

\section{Reference}

Klein-Collins, R. (2010). Fueling the race to postsecondary success: A 48-institution study of prior learning assessment and adult student outcomes. Chicago IL: CAEL.

\section{Athabasca University $\mathbf{I}$}

